\title{
REPORT ON THE HYPOTHESIS AND RESEARCH SECTION COMMUNICATION SURVEY
}

\author{
Kristine M. Alpi, MLS, MPH, AHIP ${ }^{1}$ and Brooke L. Billman, MA, AHIP ${ }^{2}$
}

The Research Section (RS) of the Medical Library Association (MLA) has published Hypothesis, an open access journal formerly structured as a newsletter, since Summer 1987. In order to plan for the future of RS' research-related communications and strategies, the RS Executive Board and the Hypothesis Editorial Board decided to seek information from the health sciences information ( $\mathrm{HSI}$ ) community about their engagement with and interest in publishing in Hypothesis.

\section{Objective}

The purpose of this investigation was to gain insight from the HSI community about the current usage of the RS open access journal Hypothesis and possible improvements that would meet the needs of those interested in learning more about HSI research.

\section{Methods}

Members of the Hypothesis Editorial Board developed an online survey to gather information from MLA members and others. It was reviewed by the RS Executive Board, but as the survey was anonymous and meant for section quality improvement, no Institutional Review Board review was pursued. The link to the 20-24 question online survey in Survey Monkey was distributed on October 7, 2015 to the RS email list, announced in the October 15 MLA Focus, and linked from the MLA webpage hosting Hypothesis content. We are unsure whether it was forwarded to other lists. The online survey was open until November 1, 2015.

\section{Results}

The survey was completed by 53 individuals. While distribution via lists is uncertain, using the MLA membership of approximately 3,000 as a denominator, the response rate was approximately $0.02 \%$. Of respondents providing demographics, 98\% $(n=42)$ were current MLA members and $61 \%(n=27)$ were current or past RS members. Forty (98\%) were based in the United States. Although most respondents were in academic health science centers $(n=27,64 \%)$ or a college/ university $(n=8,19 \%)$, five hospital librarians $(12 \%)$, one working outside of libraries (2\%), and one retiree $(2 \%)$ also responded. No library or iSchool faculty or students responded, nor did any corporate, public or specialty librarians. Responses were received from four (10\%) librarians with three or few years of experience, sixteen (38\%) with $4-10$ years, twelve (29\%) with 11-20 years, and ten $(24 \%)$ with more than 21 years. Multiple responses were permitted for many non-demographic questions resulting in percentages exceeding 100\%. In descending order for frequency, the most common avenues for becoming aware of Hypothesis were the RS member email list ( $n=20,42 \%)$, MLA Focus $(n=10,21 \%)$, other MLA publication or email list ( $n=4,8 \%)$, LISTA $(n=2,4 \%)$, CINAHL $(n=1,2 \%)$, and forwarded messages from other lists $(n=1,2 \%)$. No one reported finding it searching the web, and ten respondents (21\%) were unaware of Hypothesis. Additional avenues described in comments included being told by RS members in person at the MLA meeting $(n=1)$ and when accessing the Structured Abstract writing guidelines published in Hypothesis used for MLA meeting submissions $(n=2)$.

Several of the questions were intended for the respondents who were aware of or read Hypothesis. When asked about frequency of reading it when it was published 2-3 times per year, only ten respondents (19\%) read every issue, with an additional eleven $(21 \%)$ reading at least one, but not all, issues per year. Surprisingly, 32 $(60 \%)$ of the 53 respondents said they never read it; this presumably includes the ten who were not aware of it. Of the 17 indicating how much of each publication of Hypothesis they read, most $(n=8,47 \%)$ read around half of each issue while $29 \%(n=5)$ read less than half and $24 \%(n=4)$ read more.

Twenty respondents indicated why they read Hypothesis. Percentages for each offered reason are shown in Figure 1 and equal more than $100 \%$ as multiple responses could be selected. The three "Other" responses are summarized as 1) reading about various research methods, 2) gaining knowledge about methods and techniques in medical librarianship research, and 3) using it as a forum to publish with research mentees.

Readers were asked to rate the usefulness of content published in Hypothesis on a scale from No opinion/notapplicable (0), Not very useful (1), Somewhat useful (2), to Very useful (3) in three contexts. After removing no opinion responses, the average score for usefulness to the respondents' current position or educational program $(n=11)$ was 2.0 (SD 0.4) and the average usefulness for a desired position $(n=10)$ was similar at 1.9 (SD 0.7).

Usefulness to respondents' research whether related to position or not $(n=12)$ averaged 2.3 (SD 0.7).

Many types of content have appeared or could appear in Hypothesis. Respondents indicated the likelihood of reading each of the following content types on a scale ranged from Would not read (0) to Very likely to read (3). Table 1 shows the mean likelihood of reading this content 


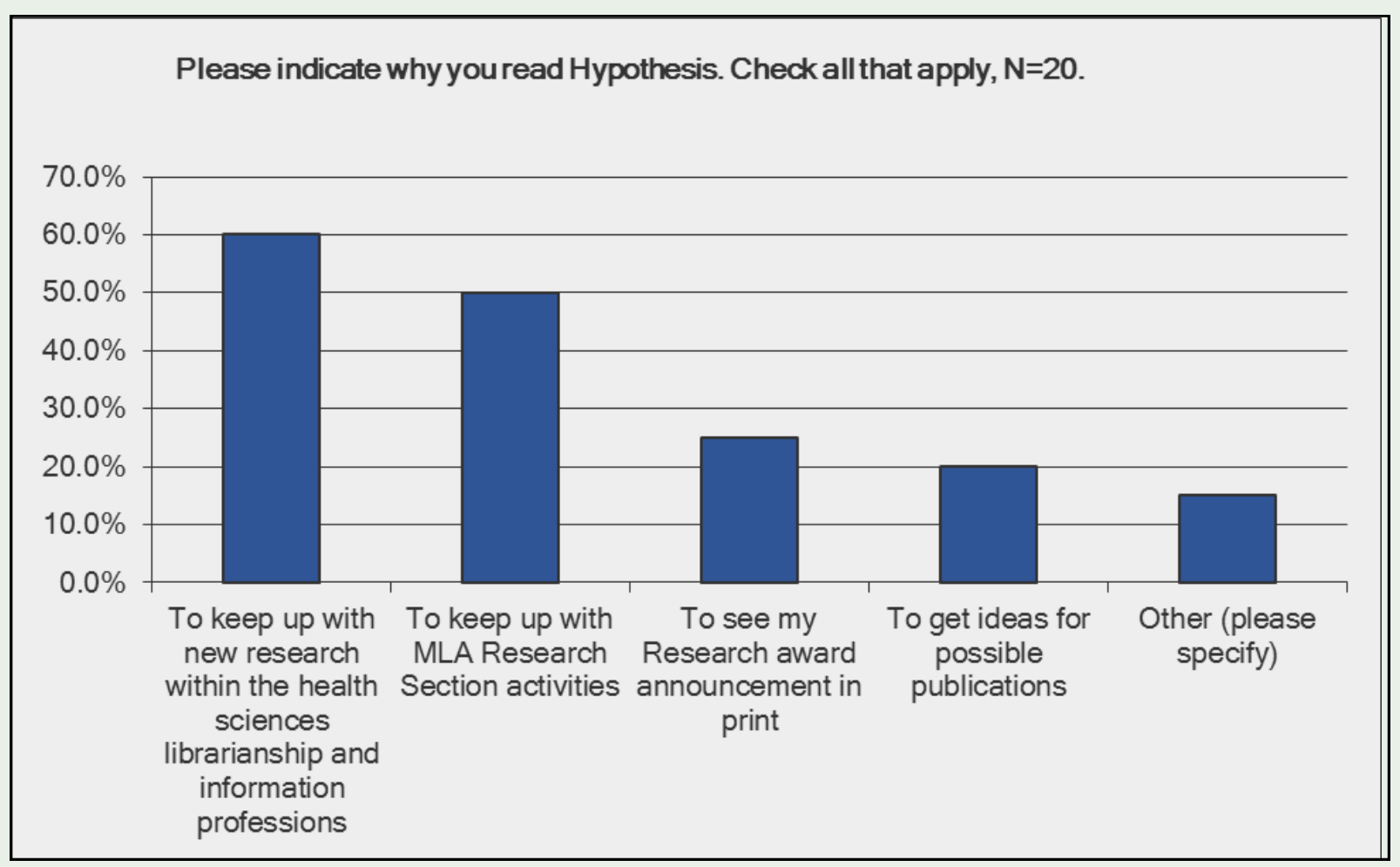

\section{Figure 1. Why respondents read Hypothesis, $\mathrm{N}=20$}

if presented in Hypothesis. Almost all content types were rated at least somewhat likely to be read (2.0). Those most often rated very likely to be read were articles reporting original research $(n=24,56 \%)$ or articles on research methods and strategies $(n=26,62 \%)$. Content suggested under "Other" were 1) failed research lessons learned, 2) reviews of library research-related textbooks, and 3) summaries of new technology applications to library science.

Another content question asked whether informal peerreviewed project write-ups would be of interest. As currently envisioned, these would be geared towards librarians who are doing projects and producing outcomes, and perhaps even changing their practices based on their results. The intent is to be able to share outcomes, lessons learned, successes, and failures so that those in the HSI community can learn from one another. Of the 46 respondents who answered this multichoice question, more than half would like to read writeups in Hypothesis $(n=27,59 \%)$ while the idea of reading these in an online, blog-type format and not having to wait for an issue of Hypothesis was preferred $(n=32$, $70 \%$ ). Only two responded that they would not be interested in reading these regardless of format. The open-ended question "What would make you more likely to read Hypothesis?" generated twelve responses which were classified into discoverability characteristics $(n=7)$ and content characteristics $(n=5)$. Ideas shared related to discoverability included:
- more awareness and communication via email (TOCs, specific reference to what Hypothesis is)

- announcements in existing channels like MLA Focus or MLA News or tweeting about new issues/article,

- individual indexing of articles for inclusion in Google Scholar and being easier to find on the web.

Content suggestions offered diverse opinions. One suggested reporting research that has been through IRB review (expedited or otherwise), another suggested featuring photography by one librarian in each issue, and two others' commented about the practice of research and publishing (shared in the respondents' own words):

- "Having my colleagues submit content about what really happens with our research efforts in libraries of all sizes not just academic medical center libraries."

- "Any journal that understands that librarians are, first and foremost, customer service agents would pique my attention. That journal would cater to real-world issues. Journals proposing that librarians are on par with actual scientists/researchers seem always to struggle with the fact that submissions aren't "scientific" enough...."

The average likelihood of contributing the content types to Hypothesis appears in Table 1. The scale ranged from Would not contribute (0) to Extremely likely (3). Mean scores all fell between Not very likely (1) to Somewhat likely (2). The types of content with the most respondents 
indicating Somewhat or Extremely likely to contribute were articles reporting original research $(n=24,56 \%)$ or articles on research methods and strategies $(n=26,62 \%)$. Other content contribution issues mentioned were original research with a research mentee and the desire only to report summaries of original research which is planned for publication in a peer-reviewed journal. For the previously mentioned informal peer reviewed project write -ups, half of respondents $(n=21,50 \%)$ would be interested in sharing these in Hypothesis while one-third $(n=14,33 \%)$ would be interested in sharing via an online, blog-type format and not waiting for an issue of Hypothesis. Others $(n=17,40 \%)$ expressed that they might be interested, but don't have a project like that in the works, or that they publish projects like that elsewhere $(n=3,7 \%)$.

When asked whether they would follow an online forum to discuss publications read in Hypothesis, a majority said Maybe $(n=26,54 \%)$ or Yes $(n=8,17 \%)$ while fourteen $(29 \%)$ indicated they would not. There were no majorities on preferred comment features of an online forum such as required sign-in $(n=14,30 \%)$, full name $(n=17,36 \%)$ or first name display $(n=7,15 \%)$, and editorial review $(n=8,17 \%)$. Many respondents $(n=18$, $38 \%$ ) had no opinion on features of such an online forum.

Of the 43 respondents who answered whether or not they had considered publishing in Hypothesis, three respondents $(7 \%)$ indicated they had published and two $(5 \%)$ were considering it. The vast majority $(n=38,88 \%)$ had neither considered submitting or had submitted an article. When asked how important a list of specific characteristics was in making a decision to submit work, more than half of respondents included peer-reviewed $(n=32,74 \%)$, no author fees $(n=30,70 \%)$, and online submission system $(n=22,51 \%)$ as being very important.
Average scores for each characteristic are provided in Table 2.

The preferred publication frequency of Hypothesis was twice a year $(n=18,43 \%)$ followed closely by more than twice a year $(n=16,38 \%)$, with eleven $(26 \%)$ preferring on an ongoing basis as content arises. Only two suggested annual publication.

Two questions in the survey were presented only to RS members. The first asked about the process and amount of a possible stipend for the Hypothesis editor. Almost half $(n=13,45 \%)$ indicated a majority vote of $R S$ members should be required to approve spending dues money on a stipend for the Hypothesis editor regardless of the amount. Only three (10\%) felt it should be up to the editor whether to request a stipend for editing Hypothesis. In terms of the amount, the responses are listed in order of frequency:

- A stipend up to $\$ 100$ per issue seems reasonable. $(n=14,48 \%)$

- A stipend up to $\$ 100$ per year, regardless of the number of issues, seems reasonable. $(n=5,17 \%)$

- No stipend should be offered. $(n=3,10 \%)$

Five usable comments were offered. Two respondents raised questions to inform the process - is a stipend typical; is there a standard for this type of work; what is the level of effort on the part of the editor; and is a stipend needed to attract a responsible editor? The other three comments related to the amount, suggesting 1 ) it should be tied to the overall MLA operating budget, 2) a recommendation of $\$ 250$ as more reasonable considering all the work involved, and 3) that it seems reasonable but not knowing whether $\$ 100$ an issue or $\$ 100$ a year would be needed.

\begin{tabular}{|l|l|l|}
\hline & $\frac{\text { Reading Likelihood }}{\text { Mean Score }}$ & $\begin{array}{l}\text { Contributing Likeli- } \\
\text { hood Mean Score }\end{array}$ \\
\hline $\begin{array}{l}\text { Articles reporting original research by health sciences librarians/ } \\
\text { information professionals (HSLIP) }\end{array}$ & 2.5 & 1.7 \\
\hline $\begin{array}{l}\text { Articles on research methods or strategies that have been/could } \\
\text { be used by HSLIP }\end{array}$ & 2.5 & 1.6 \\
\hline Summaries of research conferences or training opportunities & 2.2 & 1.1 \\
\hline $\begin{array}{l}\text { Summaries of original health informatics and librarianship disser- } \\
\text { tations and theses. }\end{array}$ & 2.0 & 1.0 \\
\hline $\begin{array}{l}\text { Abstracts of award-winning presentations at MLA annual and } \\
\text { chapter meetings }\end{array}$ & 2.0 & 1.2 \\
\hline Announcements of research conferences or training opportunities & 2.0 & 1.3 \\
\hline Announcements of research funding opportunities & 1.6 & 1.2 \\
\hline
\end{tabular}

Table 1. Likelihood of Reading or Contributing Content to Hypothesis, $\mathbf{N = 4 1 - 4 3 .}$ 


\begin{tabular}{|l|l|l|}
\hline & $\begin{array}{l}\text { Average rating } \\
\left(\begin{array}{l}\text { =Not important, 1=Not very important, } \\
\text { 2=Somewhat important, 3=Very important })\end{array}\right.\end{array}$ & Response counts \\
\hline Peer reviewed & 2.7 & 43 \\
\hline No author fees & 2.6 & 43 \\
\hline Indexed by PubMed & 2.4 & 43 \\
\hline Online submission system & 2.3 & 43 \\
\hline Time from acceptance to publication & 2.3 & 43 \\
\hline Open access & 2.2 & 43 \\
\hline Download statistics available & 1.9 & 42 \\
\hline Online peer review system & 1.8 & 42 \\
\hline Indexed by LISTA & 1.8 & 42 \\
\hline Indexed by CINAHL & 1.7 & 43 \\
\hline Public commenting available & 1.0 & 42 \\
\hline
\end{tabular}

\section{Table 2. Potential Authors' Interest in Various Publication Characteristics}

Responses for the second question ( $\mathrm{N}=29)$ about how members feel about Hypothesis as part of the Research Section activities are listed in order of frequency of response below:

- I would like to see more opportunities for members to be involved in Hypothesis. $(n=18,62 \%)$

- I am proud that our Section produces a peer reviewed online journal. $(n=16,55 \%)$

- I have been disappointed in the absence of Hypothesis issues in the recent past. $(n=9,31 \%)$

- I don't give any thought to Hypothesis. ( $n=7,24 \%)$

- Hypothesis is redundant with other online journal or newsletter publications. $(n=2,7 \%)$

- Hypothesis is redundant with other avenues of section communication available. $(n=1,3 \%)$

Five respondents provided comments for the Research Section to consider. Two related to awareness of Hypothesis, with one having learned about Hypothesis years ago but having forgotten about it until this survey and the other having not stumbled upon Hypothesis in spite of being an RS member for years. Two comments related to the various features of Hypothesis. For one respondent, the importance of various features in choosing to publish depended on the type of publication; for original research indexing and peer review is very important, but for how-to type method articles, conference summaries, or critically appraised topics, those characteristics are not as important. The fifth comment is quoted here directly: "In theory I like Hypothesis, but it doesn't give enough back for the effort put into it...Lack of PubMed indexing, inability to see distinct articles without looking at the whole issue, etc...It seems too much like a newsletter and nothing like a journal."

Finally, the majority of respondents ( $n=33,75 \%)$ preferred to learn about the survey results from an MLA Focus announcement. Additional avenues were posting to the MLA RS section list ( $n=22,50 \%)$ or linked from the RS website $(n=19,43 \%)$. Six respondents (14\%) preferred the EBLIP list.

\section{Discussion}

A limitation of this study is that it only describes the usage of Hypothesis by respondents who were primarily MLA members in the United States. The online usage data for the RS website which includes Hypothesis shows that only $34 \%$ of page views are from the United States with the next highest countries as China (22\%), Great Britain $(7 \%)$ and Italy and the Russian Federation with $4 \%$ each. This suggests an international audience for Hypothesis and other RS communications that did not participate in this survey. As no responses were received from library or iSchool faculty or students, it is unclear whether Hypothesis has value for educational activities outside of its primary audience of practicing librarians.

It is not surprising that there is a lack of awareness of Hypothesis since the last issue published was Summer 2014. While it seems that there is an audience for many types of content based on the likelihood of reading scores, it is less certain whether there are sufficient potential authors to provide this content given the likelihood to contribute. 
Hypothesis is an MLA RS communication tool and ultimately decisions about the value of the journal related to the work involved in its production are internal. The RS leadership intends to use the feedback gathered from this survey to improve RS communication of research-related content to a variety of audiences. The findings will be disseminated through MLA Focus and email list postings with a link to this specific article in Hypothesis.

Presenting the findings in this manner allows for both the indexing and discoverability requested by survey respondents, but also shares our questions and methodology with other organizations planning to evaluate their communication strategies.

\section{Acknowledgements}

Thank you to all the respondents who took the time to participate in the survey. The Hypothesis Editorial Board and other RS members who contributed to developing this survey were Kristine M. Alpi, Brooke L. Billman, Leslie Behm, Ellen Detlefsen, Jonathan Eldredge, and Heather Holmes.

\section{Author Affiliations}

${ }^{1}$ Director, William Rand Kenan, Jr. Library of Veterinary Medicine, North Carolina State University, Raleigh, NC; kmalpi@ncsu.edu

2 AZHIN \& Special Projects Librarian, University of Arizona Health Sciences Library, University of Arizona, Tucson, AZ; brooke.billman@ahsl.arizona.edu 